\title{
Staying connected in the COVID-19 pandemic: a medical center's experience to synchronize information across two branches of emergency department to enhance communication
}

\author{
Chen-Hao Liao $^{1} \wedge$, Yung-Lun Tsai ${ }^{1 \wedge}$, Tse-Hao Chen ${ }^{1} \wedge$, Wei-Yang Chi ${ }^{1 \wedge}$, Shih-Yi Yang ${ }^{1}$, \\ Wen-Han Chang ${ }^{1,2,3,4} \wedge$, Weide Tsai ${ }^{1,2,3} \wedge$ \\ ${ }^{1}$ Department of Emergency Medicine, Mackay Memorial Hospital, Taipei, Taiwan; ${ }^{2}$ Department of Medicine, Mackay Medical College, New Taipei \\ City, Taiwan Hospital, Taipei, Taiwan; ${ }^{3}$ Mackay Medicine, Nursing and Management College, Taipei, Taiwan; ${ }^{4}$ Institute of Mechatronic Engineering, \\ National Taipei University of Technology, Taipei, Taiwan \\ Correspondence to: Weide Tsai. No. 92, Sec. 2, Zhongshan N. Rd., Taipei City 10449, Taiwan. Email: weidetsai@gmail.com.
}

Received: 11 February 2021; Accepted: 15 July 2021; Published: 30 November 2021.

doi: $10.21037 / \mathrm{ht}-21-10$

View this article at: https://dx.doi.org/10.21037/ht-21-10

\section{Background}

Coronavirus disease 2019 (COVID-19), a potentially fatal disease caused by SARS-CoV-2, is transmitted through respiratory droplets, making it highly contagious (1). The condition had its first outbreak in late December 2019 in Wuhan, Hubei Province, China, and has already caused over 1 million global deaths in less than a year as the beginning of November 2020 (2). Containment measures such as social distancing or "stay-at-home" orders were issued by the infection control officials of various countries, profoundly impacting the way people live and interact with each other.

Taiwan has been a relatively safe haven up until this moment. Before adequate reports came to the surface, the Taiwan Centers for Disease Control (CDC) has been taking action as far as early January 2020, and was quick to institute the Central Epidemic Command Center (CECC), establishing a complete chain of command down to the local health system to respond in a timely manner to the global pandemics (3). The entire strategic plan has been quickly issued initially and further revised by the CECC on an ongoing basis as the epidemic evolves.

To limit the spread of the epidemics, frontline health workers have the responsibility to keep up with the scientific literature and remain up-to-date with all the official announcements and orders down the chain of command. However, working in the emergency department (ED) environment is already chaotic and stressful. Compared with non-ED staff, ED workers are prone to develop more depression, anxiety, and burnout tendency, mostly from communication loads, frequent interruptions in information exchange, etc. (4). Having an effective way to deal with all the information is definitely crucial to both the quality of care and healthcare personnel's wellbeing.

We will present our method to provide synchronized information to the staff and review our method's underlying impact in this article.

\section{How we stay connected}

During the initial peak of the pandemic, our department conducted a daily online conference call via an instant messaging app every morning around $9 \mathrm{AM}$. The department chief chaired the meeting, which usually lasted about 15 to 30 minutes.

At the beginning of the meeting, the chairman would

\footnotetext{
^ ORCID: Chen-Hao Liao, 0000-0001-6570-1754; Yung-Lun Tsai, 0000-0001-7082-234X; Tse-Hao Chen, 0000-0002-6370-7068; WeiYang Chi, 0000-0001-5295-156X; Wen-Han Chang, 0000-0002-2071-7258; Weide Tsai, 0000-0001-7859-2032.
} 
provide a concise briefing on the information from the CECC daily updates, then a summary regarding COVID-19 in our hospital based on the previous day data-including the number of the conducted COVID screening tests, the suspected cases' test results, and further disposition respectively. Then the staple of the meeting focused on new rules and structural changes-including the newly established COVID-19 triage station, temporary isolation ward, clinical pathway and consensus regarding the suspected COVID-19 cases. At the closing moment, we had a live Q\&A section for all the participants.

\section{Communication is the key: the synchronization of the information}

Communication is a keystone to a highly-functioning team. Whether in medical emergencies or trauma resuscitations, the effectiveness of team communication and coordination is proven to be necessary to achieve success in patient care (5). Despite that, we still have two roadblocks to overcome.

Firstly, our staff operates in the ED across two branches of the Mackay Memorial Hospital, the Taipei and the Tamsui branch. The Taipei branch is an urban private tertiary care hospital and an academic medical center located in the central part of Taipei City. The Tamsui branch is also a tertiary care center, located in the northern part of New Taipei City, 15 kilometers apart from the Taipei branch. The way we conduct our conference call on an instant messaging app provides the opportunity for staff working in different locations to receive the valuable information precisely, in the same format, at the same time.

Secondly, our staff work in a 12-hour shift as most of the $\mathrm{ED}$ in our country, with a sign-out time at $7 \mathrm{AM}$ and $7 \mathrm{PM}$ respectively. It is challenging for everybody to be present at the same time in this type of employment structure, but the synchronization of the information must not be compromised. The way we hold the conference call at 9 AM allows our staff to first manage the most time-sensitive tasks after signing-in, then participate in the meeting. For the departing team, the meeting could be attended online with a smartphone during the commute back home or attended from the comfort of their own homes even if the staff is not working on the day.

Our use of modern technology to promote synchronicity cuts out unnecessary time delays and the potential loss of information. It also encourages constructive feedback, comments and recommendations among the staff, bringing many benefits to the quality of patient care as well as our staff's own well-being. All it takes is simply staying connected.

\section{Less is more: simplify and summarize to reduce stress}

Occupational stress from both physiological and psychological factors has always been a heavy burden on the ED staff. Physiologically, shift work puts the staff in a disadvantageous position. The disruption of circadian rhythm could lead to sleep disorders, which increases the risk of cardiovascular diseases (6). Psychologically, the massive cognitive load, attributing to the constant information exchange and interruptions, makes the staff commit more medical errors, which lead to adverse events and decreased patient satisfaction (7). Every minute in the $\mathrm{ED}$, a nurse in charge would experience 1.68 communication interactions on average (8), and every hour there would be up to 15 interruptions for the physician (9).

Traditionally, emergency medicine is based on shift work to ensure 24-hour timely patient care. Since it's impossible to completely reduce the physiological stress, it is reasonable to simplify and summarize the information to reduce the psychological stress for the staff.

\section{Conclusions}

Aiming to reduce the mental burdens of our ED staff by synchronizing the information across all the staff is a simple yet effective way to solve a piece of long-lasting problems that we could hardly solve completely. This method is only one of the ways to improve our effectiveness as a team, and we will keep brainstorming ways for our team to find more peace amidst the chaos in the future.

\section{Acknowledgments}

Funding: None.

\section{Footnote}

Provenance and Peer Review: This article was a standard submission to the journal. The article did not undergo external peer review.

Conflicts of Interest: All authors have completed the ICMJE 
uniform disclosure form (available at https://dx.doi. org/10.21037/ht-21-10). The authors have no conflicts of interest to declare.

Ethical Statement: The authors are accountable for all aspects of the work in ensuring that questions related to the accuracy or integrity of any part of the work are appropriately investigated and resolved.

Open Access Statement: This is an Open Access article distributed in accordance with the Creative Commons Attribution-NonCommercial-NoDerivs 4.0 International License (CC BY-NC-ND 4.0), which permits the noncommercial replication and distribution of the article with the strict proviso that no changes or edits are made and the original work is properly cited (including links to both the formal publication through the relevant DOI and the license). See: https://creativecommons.org/licenses/by-nc-nd/4.0/.

\section{References}

1. Guan WJ, Ni ZY, Hu Y, et al. Clinical Characteristics of Coronavirus Disease 2019 in China. N Engl J Med 2020;382:1708-20.

2. JHCRC. COVID-19 Map 2020. Available online: https:// coronavirus.jhu.edu/map.html

doi: $10.21037 /$ ht $-21-10$

Cite this article as: Liao CH, Tsai YL, Chen TH, Chi WY, Yang SY, Chang WH, Tsai W. Staying connected in the COVID-19 pandemic: a medical center's experience to synchronize information across two branches of emergency department to enhance communication. Health Technol 2021;5:16.
3. CDC T. Taiwan CDC announces activation of Central Epidemic Command Center (CECC) for Severe Special Infectious Pneumonia to comprehensively prevent novel coronavirus pneumonia outbreak in China and ensure health of Taiwanese public. 2020 Available online: https:// www.cdc.gov.tw/Category/ListContent/DORF6HpBCcnAc7p4PDSGQ?uaid=vmv22PiH7-k3K-yh6FkmKw

4. Basu S, Qayyum H, Mason S. Occupational stress in the ED: a systematic literature review. Emerg Med J 2017;34:441-7.

5. Ford K, Menchine M, Burner E, et al. Leadership and Teamwork in Trauma and Resuscitation. West J Emerg Med 2016;17:549-56.

6. Hartenbaum N P, Zee P C. Shift work and sleep optimizing health, safety, and performance. J Occup Environ Med 2011;53:S1-10.

7. Jeanmonod R, Boyd M, Loewenthal M, et al. The nature of emergency department interruptions and their impact on patient satisfaction. Emerg Med J 2010;27:376-9.

8. Woloshynowych M, Davis R, Brown R, et al. Communication patterns in a UK emergency department. Ann Emerg Med 2007;50:407-13.

9. Chisholm CD, Collison EK, Nelson DR, et al. Emergency department workplace interruptions: are emergency physicians "interrupt-driven" and "multitasking"? Acad Emerg Med 2000;7:1239-43. 